\title{
Effect of obesity and low back pain on spinal mobility: a cross sectional study in women
}

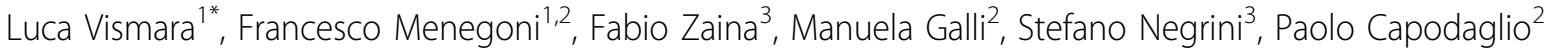

\begin{abstract}
Background: obesity is nowadays a pandemic condition. Obese subjects are commonly characterized by musculoskeletal disorders and particularly by non-specific chronic low back pain (CLBP). However, the relationship between obesity and CLBP remains to date unsupported by an objective measurement of the mechanical behaviour of the spine and its morphology in obese subjects. Such analysis may provide a deeper understanding of the relationships between function and the onset of clinical symptoms.

Purpose: to objectively assess the posture and function of the spine during standing, flexion and lateral bending in obese subjects with and without CLBP and to investigate the role of obesity in CLBP.
\end{abstract}

Study design: Cross-sectional study

Patient sample: thirteen obese subjects, thirteen obese subjects with CLBP, and eleven healthy subjects were enrolled in this study.

Outcome measures: we evaluated the outcome in terms of angles at the initial standing position (START) and at maximum forward flexion (MAX). The range of motion (ROM) between START and MAX was also computed.

Methods: we studied forward flexion and lateral bending of the spine using an optoelectronic system and passive retroreflective markers applied on the trunk. A biomechanical model was developed in order to analyse kinematics and define angles of clinical interest.

Results: obesity was characterized by a generally reduced ROM of the spine, due to a reduced mobility at both pelvic and thoracic level; a static postural adaptation with an increased anterior pelvic tilt. Obesity with CLBP is associated with an increased lumbar lordosis.

In lateral bending, obesity with CLBP is associated with a reduced ROM of the lumbar and thoracic spine, whereas obesity on its own appears to affect only the thoracic curve.

Conclusions: obese individuals with CLBP showed higher degree of spinal impairment when compared to those without CLBP. The observed obesity-related thoracic stiffness may characterize this sub-group of patients, even if prospective studies should be carried out to verify this hypothesis.

\section{Introduction}

Obesity is recognised as a major public health problem in industrialized countries and it is associated with various musculoskeletal disorders, including impairment of the spine [1-3] and osteoarthritis [4,5]. The prevalence of osteoarthritis in obese patients is reported to be $34 \%$ (17\% at knee, $7 \%$ at spine level and $10 \%$ other districts), with a significant correlation between body mass index

\footnotetext{
* Correspondence: lucavisma@libero.it

'Orthopaedic Rehabilitation Unit and Clinical Lab for Gait Analysis and Posture, Ospedale San Giuseppe, Istituto Auxologico Italiano, IRCCS, Via Cadorna 90, 1-28824, Piancavallo (VB), Italy
}

(BMI) and functional joints impairment [6]. The reported prevalence of low back pain (LBP) was $22 \%$ on 5724 obese adults 60 years or older, with a linear correlation between LBP and BMI [7].

While body weight is only a weak risk factor for LBP [7], whether obesity is correlated with LBP is still under debate: the association is generally stronger in large population studies than in smaller or occupational studies [7-11]. The BMI-pain association is consistent with what has been observed among persons with obesity seeking weight loss $[12,13]$ and in papers suggesting that weight reduction can reduce reports of musculoskeletal

\section{Biomed Central}

(C) 2010 Vismara et al; licensee BioMed Central Ltd. This is an Open Access article distributed under the terms of the Creative Commons Attribution License (http://creativecommons.org/licenses/by/2.0), which permits unrestricted use, distribution, and reproduction in any medium, provided the original work is properly cited. 
pain $[14,15]$. Being persistently overweight was associated with disk degeneration at Magnetic Resonance Imaging [16].

When differences in spine biomechanics are investigated, only a moderate link between LBP and BMI appears [3,17-23]. During stance, obese patients show an hyperextension of the lumbar spine $[24,25]$ similar to the anterior translation of the center of mass described by Whitcome in pregnant women [26]. Quantitative evidence exists that excess of weight negatively affects common daily movements, such as standing up $[27,28]$, walking [29-33], lateral bending [34], and forward flexion [35]. Few studies demonstrate a correlation between obesity and functional impairment of the spine secondary to weakness and stiffness of the lumbar muscles, possibly leading to LBP and disability [19,36-38]; moreover, there is a lack of quantitative data on spinal mobility in obese subjects who already suffer from LBP [19].

The aim of our study was to propose a quantitative protocol to describe and quantify the functional mobility of the spine during flexion and lateral bending in order to investigate the relationship between obesity and LBP.

\section{Materials and methods}

Thirty seven adult female volunteers were recruited and divided in three group: 13 obese patients without LBP (Group O) (age: $38.3 \pm 8.9$ years, BMI: $39.2 \pm 3.6 \mathrm{~kg} /$ $\left.\mathrm{m}^{2}\right), 13$ obese patients with non-specific chronic LBP [39,40] (Group cLBP) (age: $42.8 \pm 11.9$ years, BMI: 41.9 $\left.\pm 5.3 \mathrm{~kg} / \mathrm{m}^{2}\right)$, and 11 healthy women with no history of musculoskeletal complaints as the control group (Group C) (age: $31.9 \pm 8.6$ years, BMI: $20.1 \pm 1.2 \mathrm{~kg} / \mathrm{m}^{2}$ ). We considered three groups of female subjects to take into account the same gynoid mass distribution and because the prevalence of cLBP is greater in women than in men [41]. At the time of the study, cLBP patients were not under any treatment. cLBP patients were defined according to clinical examination and duration of pain [40-42], and all of them performed an X-ray to exclude secondary cLBP. The study has been approved by the local Ethical Committee and all the participants gave written informed consent.

\section{Experimental setup}

The study was conducted at the Laboratory of Gait and Posture Analysis of our Institute. Data were acquired with a 6-camera optoelectronic motion analysis system (Vicon 460, Vicon Motion Systems, Oxford, UK) operating at a sampling rate of $100 \mathrm{~Hz}$. The reflective markers were spherical with diameter of $14 \mathrm{~mm}$.

The location of the markers, the movements, the angles, and the considered parameters have been previously described [43]. Five markers were placed by the same expert operator along the spine (Figure 1): two on the thoracic (T1 and T6), two on the lumbar vertebrae

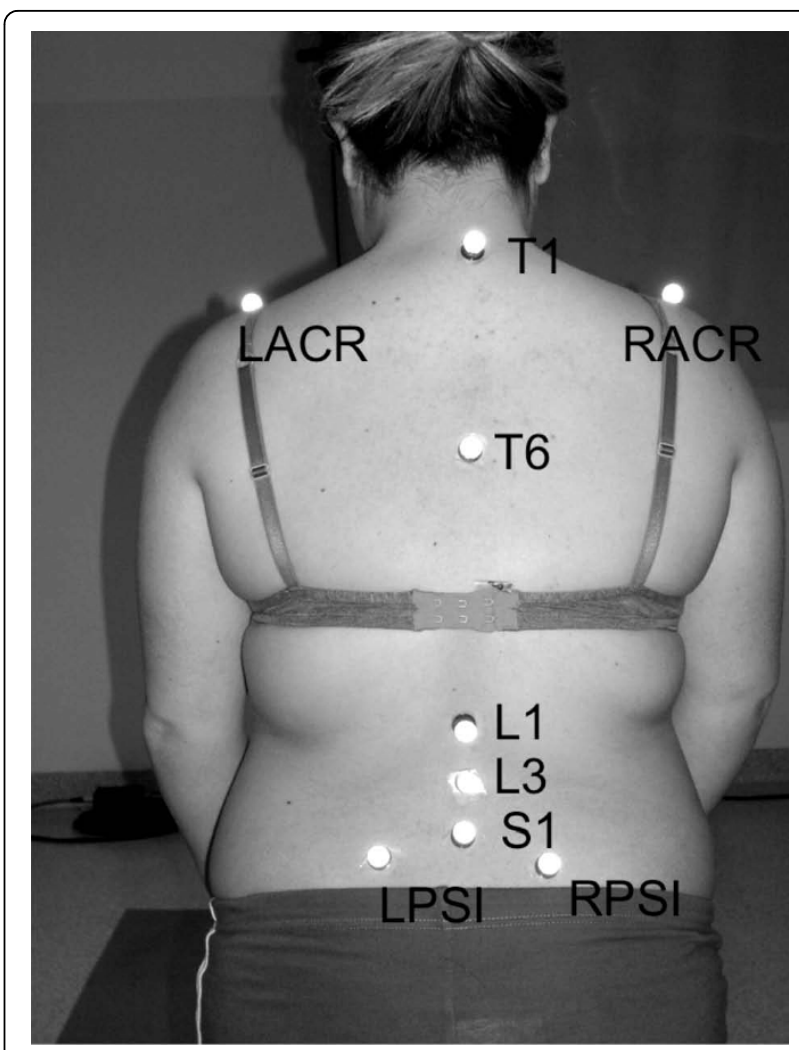

Figure 1 Marker setup. Markers were placed on superior posterior iliac spines (LPSI, RPSI), on superior anterior iliac spines (LASI, RASI not visible), on spine spinous processes (S1, L3, L1, T6, T1) and on acromions (LACR, RACR).

(L1 and L3), and one on the sacrum (S1). Four markers were positioned on the pelvis: left/right anterior (lASIS/ rASIS) and left/right posterior superior iliac spines (IPSIS/rPSIS). Two markers were then applied on the acromion of the left ( $\mathrm{ISHO}$ ) and right shoulder (rSHO).

We analyzed two different tasks: forward flexion and lateral bending both sides. Subjects were instructed to perform the test comfortably at their own preferred speed with feet apart at shoulder width. Each movement was repeated three times and the best acquisition was chosen for further analysis.

Modelling and data processing

Three-dimensional data from the optoelectronic system were processed using the multi-purpose biomechanical software SMART Analyzer (BTS, Milan, Italy). As for forward flexion, we identified the angles shown in figure 2 to characterize trunk mobility in the sagittal plane, as described in our previous study [43]. We considered: forward trunk inclination $(\alpha \mathrm{FTI})$, anterior pelvic tilt $(\alpha 1)$, angle related to lordosis $(\alpha L)$ lumbar movement $(\alpha 2)$, angle related to kyphosis $(\alpha \mathrm{K})$, and thoracic movement $(\alpha 3)$. 


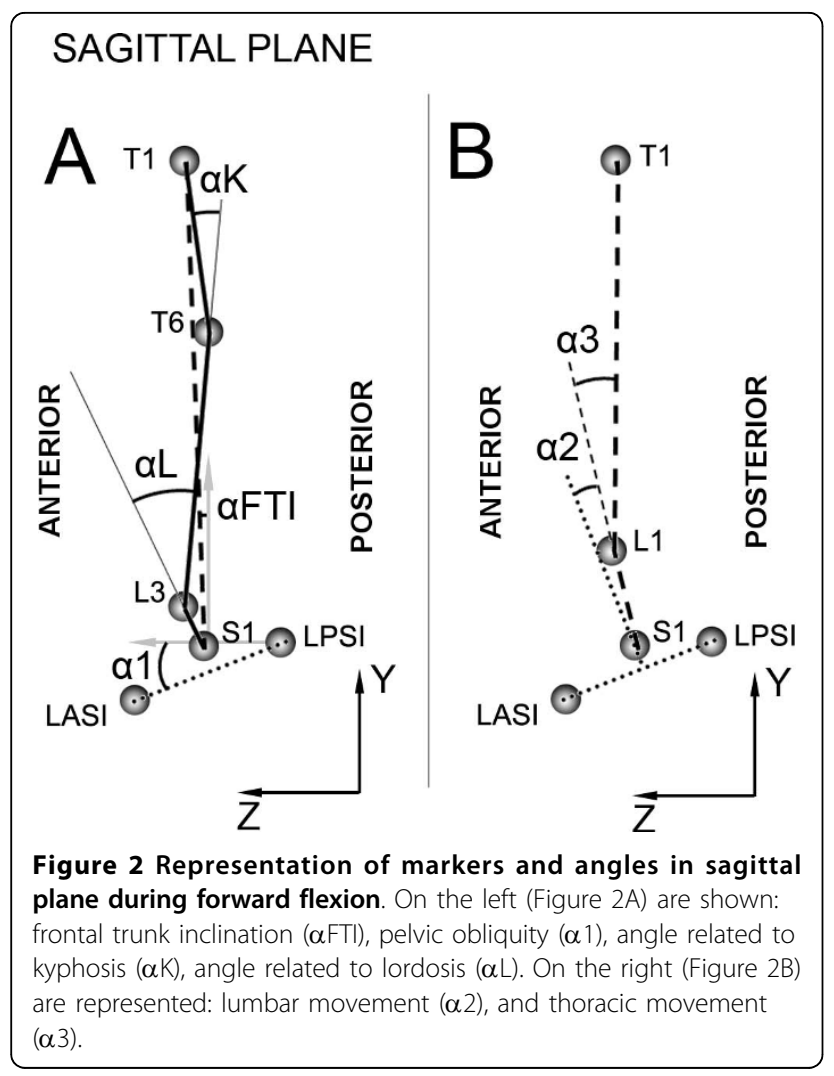

The above mentioned angles were evaluated at the initial standing position (START) and at maximum forward flexion (MAX). The range of motion (ROM) between START and MAX was also computed. As for lateral bending, similar angles were considered (Figure $3)$ : lateral trunk inclination ( $\beta \mathrm{LTI})$, pelvic obliquity $(\beta 1)$, lumbar curve $(\beta D C)$, lumbar movement $(\beta 2)$, thoracic curve $(\beta \mathrm{PC})$, thoracic movement $(\beta 3)$, and shoulders ( $\beta 4)$.

Again the ROM for each angle was evaluated, by computing the difference between maximum left and right bending. We also computed the symmetry index of lateral trunk inclination $(\beta \mathrm{LTI})$, representing the difference between the maximum left- and right-bend, and the centre of rotation (CoR), a semi-quantitative index used to locate the centre of rotation based on the trajectories of the markers in the frontal plane during the lateral bending. In particular, we identified the CoR by defining different zones delimited by the markers (Figure 4).

\section{Statistical Analysis}

The Statistica software (Statistica 6.0, StatSoft, Tulsa, OK) was used for all the analyses. The Shapiro-Wilk's W test was first used to verify the normal data distribution, and then parametric (one-way ANOVA followed by post-hoc analysis LSD test) or non-parametric (Kruskall-Wallis ANOVA followed by Mann-Whitney U-test with Bonferroni correction) tests were adopted.

\section{Results}

The analyzed groups were not homogeneous in terms of age (ANOVA, p < 0.0001) and BMI (ANOVA, p < 0.0001 ): specifically, post hoc analysis reported that there were no differences between cLBP and $\mathrm{O}$ in terms of age and BMI $(p=N S)$. C was statistically different from the other groups in terms of BMI (post hoc LSD,

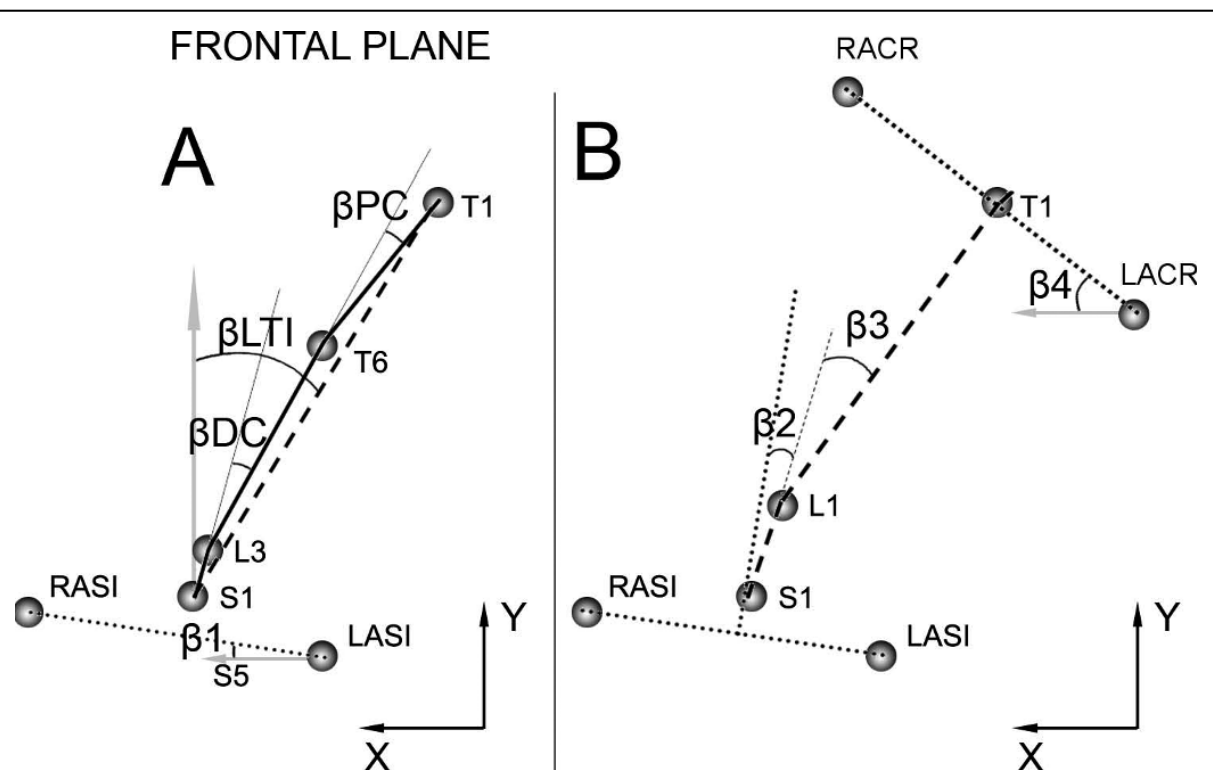

Figure 3 Representation of markers and angles in frontal plane during lateral bending. On the left (Figure 3A) are shown: lateral trunk inclination $(\beta L T I)$, pelvic obliquity $(\beta 1)$, proximal curvature $(P C)$, distal curvature $(\beta D C)$. On the right (Figure $3 B$ ) are represented: lumbar movement ( $\beta 2)$, thoracic movement ( $\beta 3)$, and angle of shoulders ( $\beta 4)$. 


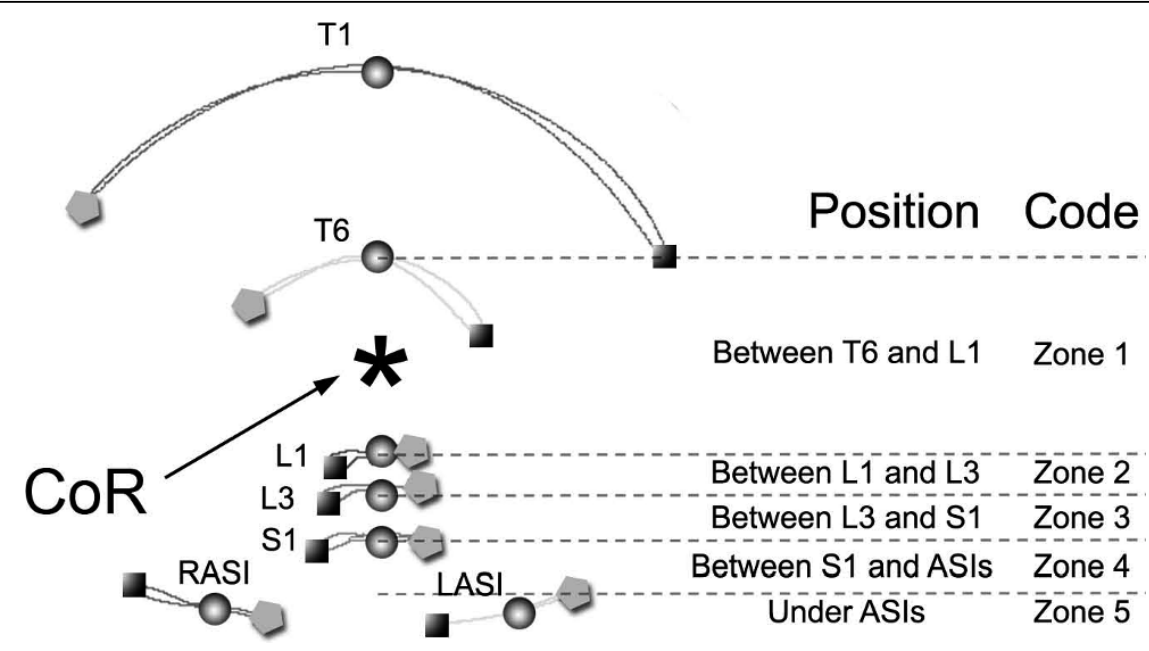

Figure 4 Lateral bending movement in frontal plane, with representation of markers (sphere: standing position, square: left bending, pentagon: right bending), and the localization of the center of rotation (CoR). On the right the code assigned to the CoR to characterize the movement. The represented normal subject was classified as Zone 1, because CoR was located between T6 and L1).

$\mathrm{p}<0.0001)$. Age was significantly different between $\mathrm{C}$ and cLBP (post hoc LSD, p = 0.01).

\section{Forward Flexion}

When compared to $\mathrm{C}$, flexion $\mathrm{ROM}$ was reduced in $\mathrm{O}$ and cLBP. In the obese subjects, this reduction was mainly influenced by the differences observed during standing posture when compared to $C$, while for cLBP it was the combination of the reduction in maximum flexion and the standing posture similar to the obese subjects. The angle related to lordosis was significantly increased in cLBP in the start position as compared to $\mathrm{C}$ and O. Similar behaviour was observed in MAX but no statistical differences in ROM were evident. The angle related to kyphosis was similar in the three groups in START, but ROM was significantly reduced in $\mathrm{O}$ and cLBP.

An increased anterior pelvic tilt angle was present in $\mathrm{O}$ and LBP, while no statistically significant reduction in ROM was observed. Lumbar movement in cLBP was significantly reduced in MAX when compared to $\mathrm{O}$ as well as to C. In START, statistically significant difference was found only between cLBP and C. The thoracic movement was significantly reduced in $\mathrm{O}$ and $\mathrm{CLBP}$ as compared to $\mathrm{C}$, not only in MAX but also in ROM (Table 1).

\section{Lateral bending}

cLBP showed a significant reduction in lateral bending and a reduced lumbar $\mathrm{ROM}$ as compared to $\mathrm{O}$ and $\mathrm{C}$. No differences among groups were observed in lumbar movement and in pelvic obliquity.

The thoracic curve was statistically different among the three groups, with cLBP yielding the worst results. cLBP also showed a significant reduction in thoracic and shoulder movements as compared to $\mathrm{O}$ and $\mathrm{C}$ (Table 2).
The qualitative analysis of lateral bending by locating the CoR showed different trajectories among groups: subjects in C showed an "hourglass" shape (Figure 5A), while $\mathrm{O}$ and CLBP showed a "cone" shape (Figure $5 \mathrm{~B}$ and Figure 5C). CoR was located between L1 and L3 in $\mathrm{C}$ (CoR Zone: 2) and between S1 and ASIS in O and cLBP (CoR Zone: 5; Mann-Whitney $\mathrm{p}=0.007$ and $\mathrm{p}=$ 0.012 respectively).

\section{Discussion}

No differences between cLBP and $\mathrm{O}$ has been found in terms of age and BMI ( $\mathrm{p}=\mathrm{NS}$ ) while, as expected, C was statistically different from other groups in terms of BMI. Age was the only unexpected significant difference between $C$ and cLBP. An age difference may well play a role in obese patients and account for the results obtained by comparisons with controls. However, all the groups were in working age, which is usual in LBP studies, which in turn consider the whole range of working ages.

Our analysis has revealed biomechanical differences in spinal mobility between $\mathrm{C}$ and $\mathrm{O}$ under static and dynamic conditions. The differences are more pronounced when comparing obese patients with to those without LBP. Prospective studies are needed to prove a cause-effect relationship, but still the gradient of differences observed in the three groups seems to support the hypothesis that obesity modifies spinal posture and function favouring the onset of cLBP. Postural analysis shows significant differences at lumbar and pelvic level among groups. Obesity seems to induce an increase in anterior pelvic tilt while maintaining a normal lumbar lordosis under static conditions. Spinal posture and 
Table 1 Main results about the forward flexion movement.

\begin{tabular}{|c|c|c|c|c|c|}
\hline & & $\mathrm{C}$ & 0 & CLBP & \\
\hline & & Mean (SD) & Mean (SD) & Mean (SD) & ANOVA \\
\hline \multicolumn{6}{|l|}{ Sagittal Plane } \\
\hline \multirow{3}{*}{$\begin{array}{l}\text { Forward trunk inclination } \\
\qquad(\alpha \mathrm{FTI})[\mathrm{deg}]\end{array}$} & START $(*)$ & $1.2(2.7)$ & $5.0(2.5)$ & $4.0(3.5)$ & $\S p=0.0093$ \\
\hline & $\operatorname{MAX}(* *)$ & $119.4(9.2)$ & $112.1(7.5)$ & $103.9(14.8)$ & $p=0.0056$ \\
\hline & $\operatorname{ROM}\left({ }^{* * *}\right)$ & $118.2(9.3)$ & $107.1(7.5)$ & $99.8(14.6)$ & $\S p=0.0041$ \\
\hline \multirow[t]{3}{*}{ Anterior pelvic tilt $(\alpha 1)$ [deg] } & $\operatorname{START}(*, * *)$ & $11.2(2.4)$ & $20.9(7.8)$ & $23.9(8.6)$ & $p=0.0003$ \\
\hline & MAX & $72.7(6.5)$ & $75.2(13.7)$ & $77.1(12.4)$ & NS \\
\hline & $\mathrm{ROM}$ & $61.4(6.2)$ & $54.3(10.4)$ & $53.2(9.5)$ & NS \\
\hline \multirow{3}{*}{$\begin{array}{l}\text { Angle related to lordosis } \\
\qquad(\alpha \mathrm{L})[\mathrm{deg}]\end{array}$} & START $(* * * * *)$ & $30.2(5.2)$ & $32.7(8.6)$ & $41.0(12.9)$ & $p=0.023$ \\
\hline & $\operatorname{MAX}(*, * *, * * *)$ & $-21.3(2.6)$ & $-14.6(5.1)$ & $-5.5(8.5)$ & $\S p=0.0001$ \\
\hline & $\mathrm{ROM}$ & $51.5(5.0)$ & $47.3(5.9)$ & $46.5(15.9)$ & NS \\
\hline \multirow{3}{*}{$\begin{array}{l}\text { Lumbar movement }(\alpha 2) \\
{[\mathrm{deg}]}\end{array}$} & START $(* *)$ & $-1.7(5.1)$ & $-7.8(13.5)$ & $-15.3(14.2)$ & $\S p=0.022$ \\
\hline & $\operatorname{MAX}(* * * * *)$ & $22.8(5.2)$ & $19.2(11.0)$ & $10.9(11.3)$ & $p=0.01$ \\
\hline & ROM & $24.5(5.6)$ & $27.0(12.2)$ & $26.1(12.2)$ & NS \\
\hline \multirow{3}{*}{$\begin{array}{l}\text { Angle related to kyphosis } \\
\qquad(\alpha \mathrm{K})[\mathrm{deg}]\end{array}$} & START & 23.7 (6.4) & $25.5(4.1)$ & $24.9(5.9)$ & NS \\
\hline & $\operatorname{MAX}\left({ }^{*}\right)$ & $34.6(8.2)$ & $27.2(5.5)$ & $29.0(7.4)$ & $p=0.048$ \\
\hline & $\operatorname{ROM}\left({ }^{*}, * *\right)$ & $10.9(7.2)$ & $1.8(5.4)$ & $4.1(6.4)$ & $p=0.004$ \\
\hline \multirow{3}{*}{$\begin{array}{l}\text { Thoracic movement ( } \alpha 3) \\
{[\mathrm{deg}]}\end{array}$} & START & $-10.2(6.7)$ & $-9.0(14.6)$ & $-4.9(9.6)$ & NS \\
\hline & $\operatorname{MAX}\left({ }^{*}, * *\right)$ & $33.9(5.2)$ & $25.5(6.6)$ & $23.4(9.2)$ & $p=0.003$ \\
\hline & $\operatorname{ROM}\left({ }^{* * *}\right)$ & $44.1(8.5)$ & $34.5(10.0)$ & $28.2(9.6)$ & $p=0.001$ \\
\hline
\end{tabular}

Trunk, pelvis, lumbar and thoracic values were used in case of forward flexion of the considered segment, negative values otherwise. Negative values of the angle related to lordosis were used to highlight a kyphosis curve of the lordosis segment.

$\S$ Kruskall-Wallis ANOVA,

* differences between $C$ and $O(p<0.05)$

** differences between C and LBP $(p<0.05)$

*** differences between $\mathrm{O}$ and LBP $(p<0.05)$.

Table 2 Main results about the lateral bending movement.

\begin{tabular}{|c|c|c|c|c|c|}
\hline & & C & 0 & CLBP & \\
\hline Frontal Plane & & Mean (SD) & Mean (SD) & Mean (SD) & ANOVA \\
\hline \multirow{2}{*}{$\begin{array}{l}\text { Lateral trunk inclination } \\
(\beta\llcorner\mathrm{LI})[\mathrm{deg}]\end{array}$} & START & $-0.2(1.0)$ & $0.7(1.5)$ & $0.5(1.7)$ & $\S N S$ \\
\hline & $\operatorname{ROM}(* * * * *)$ & $77.8(13.7)$ & $80.7(8.0)$ & $60.7(21.3)$ & $p=0.005$ \\
\hline \multirow[t]{2}{*}{ Pelvic obliquity $(\beta 1)$ [deg] } & START & $-0.5(1.7)$ & $0.0(1.6)$ & $-0.2(2.6)$ & $\S N S$ \\
\hline & $\mathrm{ROM}$ & $12.1(2.6)$ & $15.2(4.8)$ & $11.7(5.6)$ & $\S N S$ \\
\hline \multirow[t]{2}{*}{ Lumbar curve $(\beta D C)$ [deg] } & START & $1.9(4.6)$ & $2.1(3.1)$ & $1.5(5.5)$ & NS \\
\hline & $\operatorname{ROM}(* * * * *)$ & $46.0(7.0)$ & $43.9(11.3)$ & $29.4(11.8)$ & $p=0.0007$ \\
\hline \multirow{2}{*}{$\begin{array}{l}\text { Lumbar movement }(\beta 2) \\
\text { [deg] }\end{array}$} & START & $-1.9(1.7)$ & $-0.9(3.0)$ & $-1.1(4.2)$ & $\S N S$ \\
\hline & $\mathrm{ROM}$ & $20.1(8.2)$ & $26.6(9.3)$ & $21.3(16.8)$ & $\S N S$ \\
\hline \multirow[t]{2}{*}{ Thoracic curve $(\beta P C)$ [deg] } & START & $2.2(2.3)$ & $0.4(3.1)$ & $0.1(3.2)$ & NS \\
\hline & $\operatorname{ROM}\left(*^{* * *},{ }^{* * *}\right)$ & $42.2(9.0)$ & $31.3(9.0)$ & $23.0(8.9)$ & $p=0.00004$ \\
\hline \multirow{2}{*}{$\begin{array}{l}\text { Thoracic movement }(\beta 3) \\
{[\mathrm{deg}]}\end{array}$} & START & $2.7(2.4)$ & $2.8(2.6)$ & $1.4(5.3)$ & NS \\
\hline & $\operatorname{ROM}(* * * * *)$ & $59.2(9.7)$ & 50.5 (11.8) & 35.5 (12.9) & $p=0.00007$ \\
\hline Symmetry [deg] & & $-1.4(2.5)$ & $0.6(5.2)$ & $2.5(6.8)$ & NS \\
\hline COR weight & $(* * *)$ & Zone 2 & Zone 5 & Zone 5 & $\S p=0.012$ \\
\hline
\end{tabular}

Positive values were used in case of right bending of the segment.

$\S$ Kruskall-Wallis ANOVA,

* differences between $C$ and $O(P<0.05)$

** differences between $C$ and LBP $(P<0.05)$

*** differences between $O$ and LBP $(P<0.05)$. 


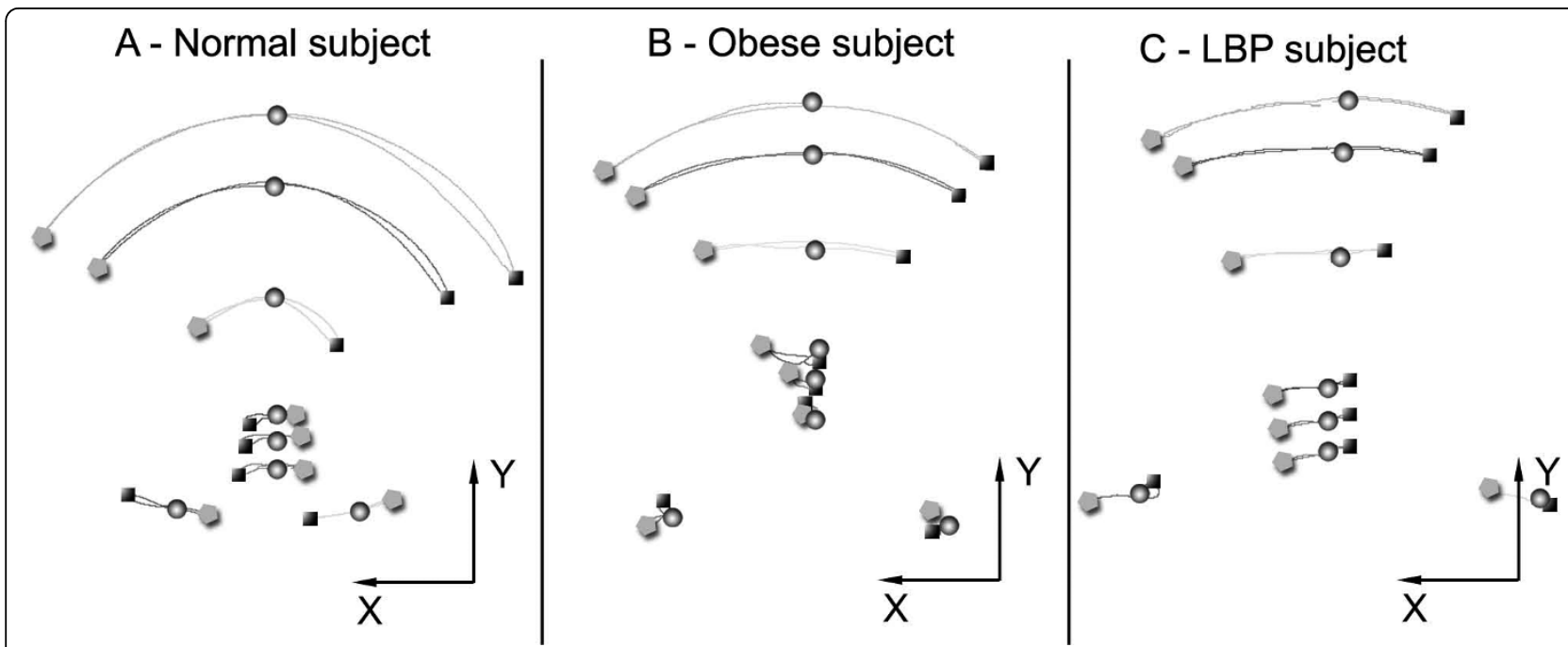

Figure 5 Lateral bending movement represented in frontal plane (C1, T1, T6, L1, L3, S1, LASI and RASI trajectories) for the different groups. On the left (Figure 5A) the "hourglass" shape of a normal subject, in the center (Figure 5B) the "cone" shape of a representative obese subject and on the right the "wider cone" shape of a CLBP subject.

function and this in turn could favour chronicization of LBP. The increased anterior pelvic tilt induces a greater flexion of the sacroiliac joints, and therefore a higher torque on the L5-S1 joint and discs. This possibly increases the shear forces at this level and overload the disc, thus increasing the risk of disk degeneration $[2,16,44]$. In line with Gilleard [38], we observed an increased lumbar lordosis in obese patients with cLBP.

Interestingly, women at later stages of pregnancy present the same posture [37]. Obese patients without cLBP, as women at early stages of pregnancy, seem to compensate the forward translation of the center of mass only with an increased anterior pelvic tilt. The increase of lumbar lordosis may well represent a painrelated strategy in obese patients with cLBP.

Abdominal circumference and gravity may influence the lumbar lordosis and its mobility during forward flexion or lateral bending. All these factors could impair the dynamic function of some muscles, in particular the erector spinal muscles, so that their counteraction to the anterior shear forces on the spine could be jeopardized [45]. Postural changes may therefore cause an insufficient muscle force output, but also other factors, such as inappropriate neuromuscular activation and muscular fatigue, may contribute to a reduced spinal stability during full flexion [46].

During forward flexion, we observed that thoracic ROM was significantly lower in $\mathrm{O}$ and significantly lower in cLBP as compared to $C$, while lumbar ROM remained similar among the three groups. Due to thoracic stiffness, forward flexion in $\mathrm{O}$ and particularly in cLBP appears to be performed mainly by the lumbar spine, which is most frequently involved in pain syndromes.
Thoracic stiffness with normal lumbar ROM appears to be a feature of obesity and it appears plausible that it might play a role in the onset of cLBP in obese patients.

A rehabilitative spin-off of our study is that targeted exercises for the thoracic spine could prevent the onset of cLBP in obese patients.

In lateral bending, our qualitative analysis based on the location of CoR was able to identify obese (cLBP and $\mathrm{O}$ ) from their lean counterparts, thus providing a potentially useful clinical index. Further, angular data allowed the identification of obese patients with and without cLBP. In line with McGill [45], our data showed that L3 seems to play a key role in lumbar kinematics.

It has been documented that the lumbar ROM in cLBP can be normal, making questionable its use as an outcome measure. Nevertheless the studies reported by Lehman in his review consider non-obese subjects, and to our knowledge, the lumbar and thoracic ROM have never been studied in obese subjects before $[47,48]$. Our findings show that obese subjects behave differently to normal weight subjects with and without LBP. In our opinion, this can be considered from a biomechanical point of view as a separate subgroup of cLBP patients that could benefit from a tailored treatment including specific mobilization in addition to the usual rehabilitative approach.

The main limitations of our study include:

$\triangleright$ The small sample size, due to the time-consuming tests used;

$>$ inclusion of females only, to reduce the cross-gender variability of fat mass distribution;

$\triangleright$ transversal design, to develop hypotheses to be proven in future longitudinal studies; 
$>$ absence of a not-obese cLBP cohort of patients: including such a group would have allowed to exclude that the results observed were due to cLBP only and not to CLBP and obesity. However, the biomechanical studies on cLBP in not-obese patients showed a higher degree of spinal stiffness, without important postural adjustments such as those observed in our study.

Possibly larger study samples involving non-obese cLBP patient should provide deeper understanding of the relationship between obesity and CLBP and contribute to the identification of different subgroups as the standard deviation values seems to suggest [34].

\section{Conclusion}

Our data show in obese patients static and dynamic adaptations in the kinematics of the spine: under static conditions, obesity per se seems correlated to an increased anterior pelvic tilt; under dynamic conditions, to impaired mobility of the thoracic spine. Obesity with cLBP is associated with higher spinal impairment than obesity without cLBP, and an increased lumbar lordosis. Lateral bending is performed in a qualitatively different modality when cLBP is present. It appears the most meaningful clinical test for detecting lower spinal impairments and monitor functional consequences of obesity.

According to our study, even if no cause-effect relationships can be drawn, rehabilitative interventions in obese patients should include strengthening of the lumbar and abdominal muscles as well as mobility exercises for the thoracic spine and pelvis, in line with previous studies [47,49].

The clinical usefulness of an optoelectronic approach is already widely acknowledged in gait analysis for the rehabilitation of several neurological and orthopaedic conditions [50]. Only two studies [43,51] so far has used kinematic analysis of the spine inhealthy subjects. Our study suggests that kinematics of the spine can represent a non-invasive clinically useful technique for functional investigation in various spinal conditions and evaluation of effectiveness in rehabilitation.

\section{Author details \\ 'Orthopaedic Rehabilitation Unit and Clinical Lab for Gait Analysis and Posture, Ospedale San Giuseppe, Istituto Auxologico Italiano, IRCCS, Via Cadorna 90, I-28824, Piancavallo (VB), Italy. ${ }^{2}$ Bioengineering Department, Politecnico di Milano, Italy. ${ }^{3}$ ISICO (Italian Scientific Spine Institute), Via Roberto Bellarmino 13/1, 20141 Milan, Italy.}

\section{Authors' contributions}

LV designed the study, participated in data collection and analysis, and manuscript writing; FM participated in data analysis, statistical analysis and manuscript writing; FZ participated in the definition of criteria selection of the subject and revision manuscript; MG participated in the study design and the manuscript revised; SN participated to the revision manuscript; PC partecipated to the recruitment of obese patients, study design and gave final approval to the version of the manuscript to be submitted. All the authors approved the final version of the manuscript.

\section{Competing interests}

The authors declare that they have no competing interests.

Received: 11 May 2009

Accepted: 18 January 2010 Published: 18 January 2010

\section{References}

1. Fanuele JC, Abdu WA, Hanscom B, Weinstein JN: Association between obesity and functional status in patients with spine disease. Spine 2002, 27:306-312.

2. Hangai M, Kaneoka K, Kuno S, Hinotsu S, Sakane M, Mamizuka N, Sakai S, Ochiai $\mathrm{N}$ : Factors associated with lumbar intervertebral disc degeneration in the elderly. Spine J 2008, 8(5):732-40.

3. Kostova V, Koleva M: Back disorders (low back pain, cervicobrachial and lumbosacral radicular syndromes) and some related risk factors. J Neurol Sci 2001, 192:17-25.

4. Hinton R, Moody RL, Davis AW, Thomas SF: Osteoarthritis: diagnosis and therapeutic considerations. Am Fam Physician 2002, 65:841-848.

5. Sowers M: Epidemiology of risk factors for osteoarthritis: systemic factors. Curr Opin Rheumatol 2001, 13:447-451

6. Mellin G, Harkapaa K, Vanharanta H, Hupli M, Heinonen R, Järvikoski A Outcome of a multimodal treatment including intensive physical training of patients with chronic low back pain. Spine 1993, 18(7):825-829.

7. Leboeuf-Yde C: Body weight and low back pain. A systematic literature review of 56 journal articles reporting on 65 epidemiologic studies. Spine 2000, 25:226-237.

8. Fransen M, Woodward M, Norton R, Coggan C, Dawe M, Sheridan N: Risk factors associated with the transition from acute to chronic occupational back pain. Spine 2002, 27:92-98.

9. Han TS, Schouten JS, Lean ME, Seidell JC: The prevalence of low back pain and associations with body fatness, fat distribution and height. Int J Obes Relat Metab Disord 1997, 21:600-607.

10. Andersen RE, Crespo CJ, Bartlett SJ, Bathon, Fontaine KR: Relationship between body weight gain and significant knee, hip, and back pain in older Americans. Obes Res 2003, 11:1159-1162

11. Toda Y, Segal N, Toda T, Morimoto T, Ogawa R: Lean body mass and body fat distribution in participants with chronic low back pain. Arch Intern Med 2000, 160:3265-3269.

12. Barofsky I, Fontaine KR, Cheskin LJ: Pain in the obese: Impact on healthrelated quality of life. Ann Behav Med 1998, 19:408-410.

13. Fontaine KR, Barofsky I, Andersen, Bartlett SJ, Wiersema L, Cheskin L Franckowiak SC: Impact of weight loss on pain and health-related quality of life. Quality Life Res 1999, 8:275-277.

14. Fontaine KR, Cheskin $L$, Barofsky I: Health-related quality of life in obese persons seeking treatment. J Fam Pract 1996, 43:265-270.

15. Martin K, Fontaine KR, Nicklas, Dennis KE, Goldberg AP, Hochberg MC: Weight loss and exercise walking reduce pain and improve physical functioning in overweight post-menopausal women with knee osteoarthritis. J Clin Rheumatol 2001, 7:219-223.

16. Liuke M, Solovieva $S$, Lamminen A, Luoma $K$, Leino-Arjas $P$, Luukkonen $R$, Riihimäki H: Disc degeneration of the lumbar spine in relation to overweight. Int J Obes (Lond) 2005, 29(8):903-8.

17. Dunn KM, Croft PR: Epidemiology and natural history of low back pain. Eura Medicophys 2004, 40(1):9-13.

18. Flamme $\mathrm{CH}$ : Obesity and low back pain-biology, biomechanics and epidemiology. Orthopade 2005, 34(7):652-7.

19. Janke $A E$, Collins $A$, Kozak AT: Overview of the relationship between pain and obesity: What do we know? Where do we go next?. Journal of Rehabil Res and Dev 2007, 44:245-262.

20. Leboeuf-Yde C, Kyvik KO, Bruun NH: Low back pain and lifestyle. Part IIObesity. Information from a population-based sample of 29,242 twin subjects. Spine 1999, 15:779-783.

21. Mirtz TA, Greene L: Is obesity a risk factor for low back pain? An example of using the evidence to answer a clinical question. Chiropractic \& Osteopathy 2005, 13:2.

22. Verbunt JA, Seelen HA, Vlaeyen JW, Heijden van de GJ, Heuts PH, Pons K, Knottnerus JA: Disuse and deconditioning in chronic low back pain: 
concepts and hypotheses on contributing mechanisms. Eur J Pain 2003, 7(1):9-21.

23. Yip YB, Ho SC, Chan SG: Tall stature, overweight and the prevalence of low back pain in Chinese middle-aged women. Int J Obes Relat Metab Disord 2001, 25(6):887-92.

24. Fabris de Souza SA, Faintuch J, Valezi AC, Sant'Anna AF, Gama-Rodrigues JJ, de Batista Fonseca IC, de Melo RD: Postural changes in morbidly obese patients. Obes Surg 2005, 15(7):1013-6.

25. O'Sullivan PB, Dankaerts W, Burnett AF, Farrell GT, Jefford E, Naylor CS, O'Sullivan KJ: Effect of different upright sitting postures on spinal-pelvic curvature and trunk muscle activation in a pain-free population. Spine 2006, 31(19):E707-12.

26. Whitcome KK, Shapiro JL, Lieberman DL: Fetal load and the evolution of lumbar lordosis in bipedal hominins. Nature 2007, 450(7172):1075-8.

27. Galli M, Crivellini M, Sibella F, Montesano A, Bertocco P, Parisio C: Sit-tostand movement analysis in obese subjects. Int I Obes Relat Metab Disord 2000, 24(11):1488-92.

28. Sibella F, Galli M, Romei M, Montesano A, Crivellini M: Biomechanical analysis of sit-to-stand movement in normal and obese subjects. Clin Biomech 2003, 18(8):745-50.

29. de Souza SA, Faintuch J, Valezi AC, Sant' Anna AF, Gama-Rodrigues JJ, de Batista Fonseca IC, Souza RB, Senhorini RC: Gait cinematic analysis in morbidly obese patients. Obes Surg 2005, 15(9):1238-42.

30. Messier SP, Davies AB, Moore DT, Davis SE, Pack RJ, Kazmar SC: Severe obesity: effects on foot mechanics during walking. Foot Ankle Int 1994, 15:29-34.

31. Saibene F, Minetti AE: Biomechanical and physiological aspects of legged locomotion in humans. Eur J Appl Physiol 2003, 88(4-5):297-316, Review.

32. Spyropoulos P, Pisciotta JC, Pavlou KN, Cairns MA, Simon SR: Biomechanical Gait Analysis in obese men. Arch Phys Med Rehabil 1991, 72:1065-1070.

33. Vismara L, Romei M, Galli M, Montesano A, Baccalaro G, Crivellini M, Grugni G: Clinical implications of gait analysis in the rehabilitation of adult patients with "Prader-Willi" Syndrome: a cross-sectional comparative study ("Prader-Willi" Syndrome vs matched obese patients and healthy subjects). J Neuroengineering Rehabil 2007, 10(4):14.

34. Lund T, Nydegger T, Schlenzka D, Oxland TR: Three-Dimensional Motion Patterns During Active Bending in Patients with Chronic Low Back Pain. Spine 2002, 27(17):1865-1874.

35. Gilleard W, Smith T: Effect of obesity on posture and hip joint moments during a standing task, and trunk forward flexion motion. International Journal of Obesity 2007, 31:267-27.

36. Buckwalter JA: Maintaining and restoring mobility in middle and old age: the importance of the soft tissues. Instr Course Lect 1997, 46:459-69.

37. Larsson UE: Influence of weight loss on pain, perceived disability functional limitations in obese women. Int J Obes Relat Metab Disord 2004, 28:269-77.

38. Tsuritani I, Honda R, Noborisaka Y, Ishida M, Ishizaki M, Yamada Y: Impact of obesity on musculoskeletal pain and difficulty of daily movements in Japanese middle-aged women. Maturitas 2002, 42(1):23-30.

39. Hayden JA, van Tulder MW, Malmivaara A, Koes BW: Exercise therapy for treatment of non-specific low back pain. Cochrane Database Syst Rew 2005, 3:CD000335.

40. Negrini S, Giovannoni S, Minozzi S, Barneschi G, Bonaiuti D, Bussotti A, D'Arienzo M, Di Lorenzo N, Mannoni A, Mattioli S, Modena V, Padua L, Serafini F, Violante FS: Diagnostic therapeutic flow-charts for low back pain patients: the Italian clinical guidelines. Eura Medicophys 2006, 42:15170.

41. Schneider S, Randol D, Buchner M: Why do women have back pain more than man? A representative prevalence study in the federal repubblic in German. Clinical Journal of pain 2006, 22:738-747.

42. Airaksinen O, Brox Jl, Cedraschi C, Hildebrandt J, Klaber-Moffett J, Kovacs F Mannion AF, Reis S, Staal JB, Ursin H, Zanoli G: COST B13 Working Group on Guidelines for Chronic Low Back Pain. Chapter 4. European guidelines for the management of chronic nonspecific low back pain. Eur Spine J 2006, 15(Suppl 2):S192-300.

43. Menegoni F, Vismara L, Capodaglio P, Crivellini M, Galli M: Kinematics of trunk movements: protocol design and application in obese females. JABB - Journal of Applied Biomaterials \& Biomechanics 2008, 6(3):178-185.

44. Burkemper KM, Garris DR: Influences of obese (ob/ob) and diabetes ( $\mathrm{db} /$ $\mathrm{db}$ ) genotype mutations on lumber vertebral radiological and morphometric indices: skeletal deformation associated with dysregulated systemic glucometabolism. BMC Musculoskelet Disord 2006, 1:7-10.

45. McGill SM, Hughson RL, Parks K: Changes in lumbar lordosis modify the role of the extensor muscles. Clin Biomech 2000, 15(10):777-80.

46. Descarreaux M, Lafond D, Jeffrey-Gauthier R, Centomo H, Cantin V: Changes in the flexion relaxation response induced by lumbar muscle fatigue. BMC Musculoskelet Disord 2008, 9(1):1.

47. Lehman GL: Biomechanical assessments of lumbar spinal function. How low back pain suffers differ from normals. Implications for outcome measures research. Part I: Kinematic assessments of lumbar function. J Manip Physiol Ther 2004, 27(1):57-62.

48. Nattrass CL, Nitschke JE, Disler PB, Chou MJ, Ooi KT: Lumbar spine range of motion as a measure of physical and functional impairment: an investigation of validity. Clin Rehabil 1999, 13:211-218.

49. Nourbakhsh MR, Arab AM: Ralation between mechanical factors and incidence of low back pain. J Orthop Sports Phys Ther 2002, 32:447-460.

50. Davis RB, Ounpuu S, Tyburski, Gage GR: A gait analysis data collection and reduction technique. Hum Mov Sci 1991, 10:575-87.

51. Peharec S, Jerković R, Bacić P, Azman J, Bobinac D: Kinematic measurement of the lumbar spine and pelvis in the normal population. Coll Antropol 2007, 31(4):1039-42.

doi:10.1186/1743-0003-7-3

Cite this article as: Vismara et al.: Effect of obesity and low back pain on spinal mobility: a cross sectional study in women. Journal of NeuroEngineering and Rehabilitation 2010 7:3.

\section{Publish with Biomed Central and every scientist can read your work free of charge}

"BioMed Central will be the most significant development for disseminating the results of biomedical research in our lifetime. "

Sir Paul Nurse, Cancer Research UK

Your research papers will be:

- available free of charge to the entire biomedical community

- peer reviewed and published immediately upon acceptance

- cited in PubMed and archived on PubMed Central

- yours - you keep the copyright
BioMedcentral 